\title{
Role of gonadotropin-releasing hormone analogues in metastatic male breast cancer: results from a pooled analysis
}

Luigi Di Lauro ${ }^{1}$, Laura Pizzuti ${ }^{1}$, Maddalena Barba ${ }^{1,2}$, Domenico Sergi ${ }^{1}$, Isabella Sperduti ${ }^{3}$, Marcella Mottolese ${ }^{4}$, Carla Azzurra Amoreo ${ }^{4}$, Franca Belli ${ }^{5}$, Patrizia Vici ${ }^{1}$, Valerie Speirs ${ }^{6}$, Daniele Santini ${ }^{7}$, Ruggero De Maria ${ }^{2}$ and Marcello Maugeri-Saccà ${ }^{1,2^{*}}$

\begin{abstract}
Background: Male breast cancer is a rare malignancy. Despite the lack of prospectively generated data from trials in either the adjuvant or metastatic setting, patients are commonly treated with hormone therapies. Much controversy exists over the use of gonadotropin-releasing hormone analogues in metastatic male breast cancer patients. We conducted this study to provide more concrete ground on the use of gonadotropin-releasing hormone analogues in this setting.

Methods: We herein present results from a pooled analysis including 60 metastatic male breast cancer patients treated with either an aromatase inhibitor or cyproterone acetate as a monotherapy (23 patients) or combined with a gonadotropin-releasing hormone analogue (37 patients).

Results: Overall response rate was $43.5 \%$ in patients treated with monotherapy and $51.3 \%$ with combination therapy $(p=0.6)$. Survival outcomes favored combination therapy in terms of median progression-free survival (11.6 months versus 6 months; $p=0.05)$, 1-year progression-free survival rate (43.2\% versus $21.7 \% ; p=0.05)$, median overall survival (29.7 months versus 22 months; $p=0.05$ ), and 2 -year survival rate (64.9\% versus $43.5 \% ; p=0.05$ ).
\end{abstract}

Conclusions: In metastatic male breast cancer patients, the combined use of gonadotropin-releasing hormone analogues and aromatase inhibitors or antiandrogens seems to be associated with greater efficacy, particularly in terms of survival outcomes, compared with monotherapy. Collectively, these results encourage considering these agents in the metastatic setting.

Keywords: Male breast cancer, Metastatic disease, Gonadotropin-releasing hormone analogue, Aromatase inhibitors, Cyproterone acetate

\section{Background}

Male breast cancer $(\mathrm{MBC})$ is an uncommon malignancy accounting for less than $1 \%$ of all breast cancer (BC) cases [1], albeit its incidence is rising [2]. The hormonedriven nature of the disease was postulated in the 1940s [2] and corroborated over the past decades by studies reporting on hormone receptor expression [3, 4]. Results from the National Cancer Institute's Surveillance, Epidemiology, and End Results (SEER) database revealed

\footnotetext{
*Correspondence: maugeri@ifo.it

"Division of Medical Oncology B, "Regina Elena" National Cancer Institute, Via Elio Chianesi 53, 00144 Rome, Italy

${ }^{2}$ Scientific Direction, "Regina Elena" National Cancer Institute, Via Elio Chianesi 53, 00144 Rome, Italy

Full list of author information is available at the end of the article
}

that $92 \%$ of MBC cases were estrogen receptor-positive [4]. Thus, antiestrogen therapy currently represents the mainstay of treatment for these patients, even though the use of tamoxifen [5], aromatase inhibitors (AIs) $[6-8]$, and fulvestrant $[9,10]$ was investigated only retrospectively in small-sized cohorts. A therapeutic role for the androgen receptor (AR) was also envisioned [11-13] and corroborated by immunohistochemical analysis and gene-expression-profiling studies [3, 14]. Analysis of a large $\mathrm{MBC}$ cohort documented $\mathrm{AR}$ immunoreactivity in $64 \%$ of cases [3], and over-expression of AR-related pathway components was reported [14].

Despite the wealth of hormonal treatments that have entered the therapeutic arena, owing to the rarity of this

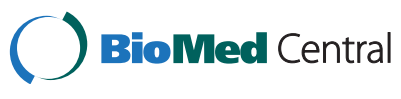

(c) 2015 Di Lauro et al.; licensee BioMed Central. This is an Open Access article distributed under the terms of the Creative Commons Attribution License (http://creativecommons.org/licenses/by/4.0), which permits unrestricted use, distribution, and reproduction in any medium, provided the original work is properly credited. The Creative Commons Public Domain Dedication waiver (http://creativecommons.org/publicdomain/zero/1.0/) applies to the data made available in this article, unless otherwise stated. 
disease and lack of prospectively generated data, a number of unsolved questions afflict daily clinical practice. A heated argument surrounds the question of whether gonadotropin-releasing hormone analogues (GnRH analogues) are worth being administered in combination with other hormonal treatments acting on peripheral targets $[7,8,13]$. This controversy was fuelled by the advent of AIs [15]. In males, AIs lead to increased levels of follicle-stimulating hormone (FSH), luteinising hormone $(\mathrm{LH})$, and testosterone (T) [16-20]. This phenomenon was observed in hypogonadal men and $\mathrm{MBC}$ patients [16-20]. For MBC patients, implications of increased $T$ levels are twofold: i) the counteraction of the block imposed by AIs through an excess of substrate and ii) a direct stimulation of cancer cells equipped with the AR [21]. Briefly, the inhibition of the hypothalamic-pituitary feedback loop, with the correlated reduction of the substrate for aromatization, was the rationale for combining AIs with $\mathrm{GnRH}$ analogues. A second, though underestimated, association strategy relates to the use of $\mathrm{GnRH}$ analogues with antiandrogens $[12,13]$. Our group reported on the antitumor activity of antiandrogens [11, 12], a finding we recently strengthened in a larger series where hints on the existence of an association between AR expression and clinical outcomes were also provided [13]. In this case, the use of antiandrogens with a GnRH analogue stemmed from the need to neutralize testicular and adrenal androgens, theorizing analogies in terms of androgen dependency between MBC and prostate cancer [13]. Indeed, our group already reported on the suppression of gonadotropins together with $\mathrm{T}$ suppression to castration levels in $\mathrm{MBC}$ patients who received cyproterone acetate (CPA) with buserelin [12]. These effects were also observed, although to a lower extent, with CPA monotherapy [11].

Therefore, there is a common theme underlying the use of GnRH analogue with antiandrogens and AIs, namely, achieving the deepest possible $\mathrm{T}$ suppression to directly or indirectly deprive cancer cells of a source of oncogenic stimuli, in the latter case by preventing the conversion of androstenedione to 17b-estradiol operated by the aromatase enzyme.

By evaluating metastatic $\mathrm{MBC}(\mathrm{mMBC})$ treated with an AI or CPA $[8,13]$, administered alone or combined with a $\mathrm{GnRH}$ analogue, we previously noted some differences favoring the association. Nevertheless, the relatively restricted number of patients analyzed hindered statistically significant comparisons. Prompted by this observation, we herein present results from a pooled analysis of these studies, with the inclusion of five additional patients, in order to gain more insights into the efficacy of GnRH analoguecontaining hormonal therapy in $\mathrm{mMBC}$ patients.

\section{Results}

Sixty men mostly treated in the first-line metastatic setting were included in the present analysis.
Patients' characteristics are illustrated in Table 1. As shown in Table 1, the groups compared did not differ by any of the variables considered. Overall, 37 patients received GnRH analogue-containing therapy (22 patients with CPA and 15 patients with an AI), and 23 patients were treated with $\mathrm{GnRH}$ analogue-free therapy (14 patients with CPA and 9 patients with an $\mathrm{AI}$ ).

Table 1 Association between clinical-pathological features and treatment received $(N=60)$

\begin{tabular}{|c|c|c|c|}
\hline Characteristic & With GnRH N (\%) & Without GnRH N (\%) & $p$ value* \\
\hline \multicolumn{4}{|l|}{ Age } \\
\hline Median & 64 & 63 & 0.79 \\
\hline Range & $24-82$ & $29-76$ & \\
\hline \multicolumn{4}{|l|}{ ECOG PS } \\
\hline Median & 1 & 1 & 0.88 \\
\hline Range & $0-2$ & $0-2$ & \\
\hline \multicolumn{4}{|c|}{$\begin{array}{l}\text { Hormone receptor } \\
\text { status }\end{array}$} \\
\hline Positive & $32(86.5)$ & 19 (82.6) & 0.99 \\
\hline Negative & $2(5.5)$ & $2(8.7)$ & \\
\hline Unknown & $3(8)$ & $2(8.7)$ & \\
\hline \multicolumn{4}{|c|}{$\begin{array}{l}\text { Adjuvant systemic } \\
\text { therapy }\end{array}$} \\
\hline Yes & $19(51)$ & $10(43.5)$ & 0.60 \\
\hline No & $18(49)$ & $13(56.5)$ & \\
\hline \multicolumn{4}{|c|}{$\begin{array}{l}\text { Prior therapy for } \\
\text { metastatic disease }\end{array}$} \\
\hline Yes & $9(24)$ & $7(30.5)$ & 0.99 \\
\hline No & $28(76)$ & $16(69.5)$ & \\
\hline \multicolumn{4}{|c|}{$\begin{array}{l}\text { Subsequent lines of } \\
C T\end{array}$} \\
\hline Median & 1 & 1 & 0.72 \\
\hline Range & $1-2$ & $1-2$ & \\
\hline \multicolumn{4}{|c|}{$\begin{array}{l}\text { Subsequent lines of } \\
\text { HT }\end{array}$} \\
\hline Median & 1 & 1 & 0.85 \\
\hline Range & $1-3$ & $1-3$ & \\
\hline \multicolumn{4}{|c|}{ Dominant disease site } \\
\hline Viscera & $24(64.9)$ & $14(60.8)$ & \\
\hline Bone & $9(24.3)$ & $8(34.8)$ & 0.98 \\
\hline Soft-tissue & $4(10.8)$ & $1(4.4)$ & \\
\hline \multicolumn{4}{|c|}{$\begin{array}{l}\text { Number of disease } \\
\text { sites }\end{array}$} \\
\hline 1 & $11(29.7)$ & $10(43.4)$ & \\
\hline 2 & $21(56.7)$ & $9(39.1)$ & 0.99 \\
\hline$\geq 3$ & $5(13.6)$ & $4(17.5)$ & \\
\hline
\end{tabular}

ECOG PS: Eastern Cooperative Oncology Group Performance Status; CT: chemotherapy; $\mathrm{HT}$ : hormone therapy *Fisher exact test 
Stage at diagnosis was I, II, III, and IV in 11 (18.3\%), $20(33.3 \%), 21(35 \%)$, and $8(13.4 \%)$ patients, respectively. Stage I-II at diagnosis was $48 \%$ in the monotherapy group and $52 \%$ in the combination group. Overall, 29 patients received adjuvant systemic therapy, 10 in the monotherapy group $(43.5 \%)$ and 19 in the combination group (51\%). In the adjuvant setting, ten patients were treated with chemotherapy, ten patients with hormone therapy, and nine patients with both chemotherapy and hormone therapy. Adjuvant hormone therapy consisted of tamoxifen in all but one patient who received goserelin. Adjuvant chemotherapy consisted of cyclophosphamide, methotrexate, and 5-fluorouracil (CMF) in 11 patients; 5-fluorouracil, doxorubicin, and cyclophosphamide or 5-fluorouracil, epirubicin, and cyclophosphamide (FAC or FEC, respectively) in 5 patients; or epirubicin, cyclophosphamide, docetaxel (EC-D) in 3 patients. Sixteen patients received previous chemotherapy and/or hormone therapy for metastatic disease: 7 out of $23(30.5 \%)$ in the monotherapy group and 9 out of $37(24 \%)$ in the combination group. The characteristics of these treatments, along with clinical outcomes, were reported in detail elsewhere $[8,13]$. Five patients treated in the first-line setting with an $\mathrm{AI}$ in monotherapy were retreated with an $\mathrm{AI}$ in association with a $\mathrm{GnRH}$ analogue after disease progression. These patients were included in the monotherapy group in the present analysis.

Overall response rate was $51.3 \%$ (19/37 patients) in patients treated with combination versus $43.5 \%$ with monotherapy (10/23 patients). The difference observed was not statistically relevant $(p=0.6)$. Median progression-free survival (mPFS) was 11.6 months $(95 \% \mathrm{CI}=10.2-13)$ in the group having received the $\mathrm{GnRH}$ analogue-containing combination and 6 months $(95 \% \mathrm{CI}=4-8)$ for patients treated with monotherapy $(p=0.05)$ (Fig. 1). One-year progression-free survival (PFS) rate also favored combination (43.2 \% versus $21.7 \%$; $p=0.05)$. Median overall survival (mOS) was 29.7 months with combination $(95 \% \mathrm{CI}=$ 20.4-39) and 22 months (95 \% CI = 15.9-28.1) with monotherapy $(p=0.05)$ (Fig. 1). Two-year survival rate was $64.9 \%$ in the combination group versus $43.5 \%$ in the monotherapy group $(p=0.05)$.

\section{Discussion}

Evidence on the therapeutic role of $\mathrm{GnRH}$ analogue as a partner for other hormonal agents in $\mathrm{mMBC}$ are scattered, gathered from case reports or small retrospective series, and overall inconsistent $[7,8,13,15]$. More generally, therapeutic decision-making for $\mathrm{mMBC}$ is not built upon level I evidence, and without appearing nihilistic, we do not foresee brighter scenarios in the near future. Not surprisingly, then, there is no agreement on whether $\mathrm{GnRH}$ analogues should be considered an integral part of the therapeutic armamentarium, or rather, their use should be evaluated on a case-by-case basis $[21,22]$. Anticipating that our results, which are retrospective in nature, are not intended to provide a definitive answer on that issue, to the best of our knowledge, this is the largest series presented so far describing the activity of GnRH analogue-containing therapy.

Before discussing our results, two introductive considerations need to be presented. As previously discussed elsewhere, we were unable to retrieve safety data for all patients included $[8,13]$. However, when available, toxicities data were consistent with the expected frequency and severity. In addition, out-of-date imaging techniques and criteria for response evaluation were used in a fraction of patients.
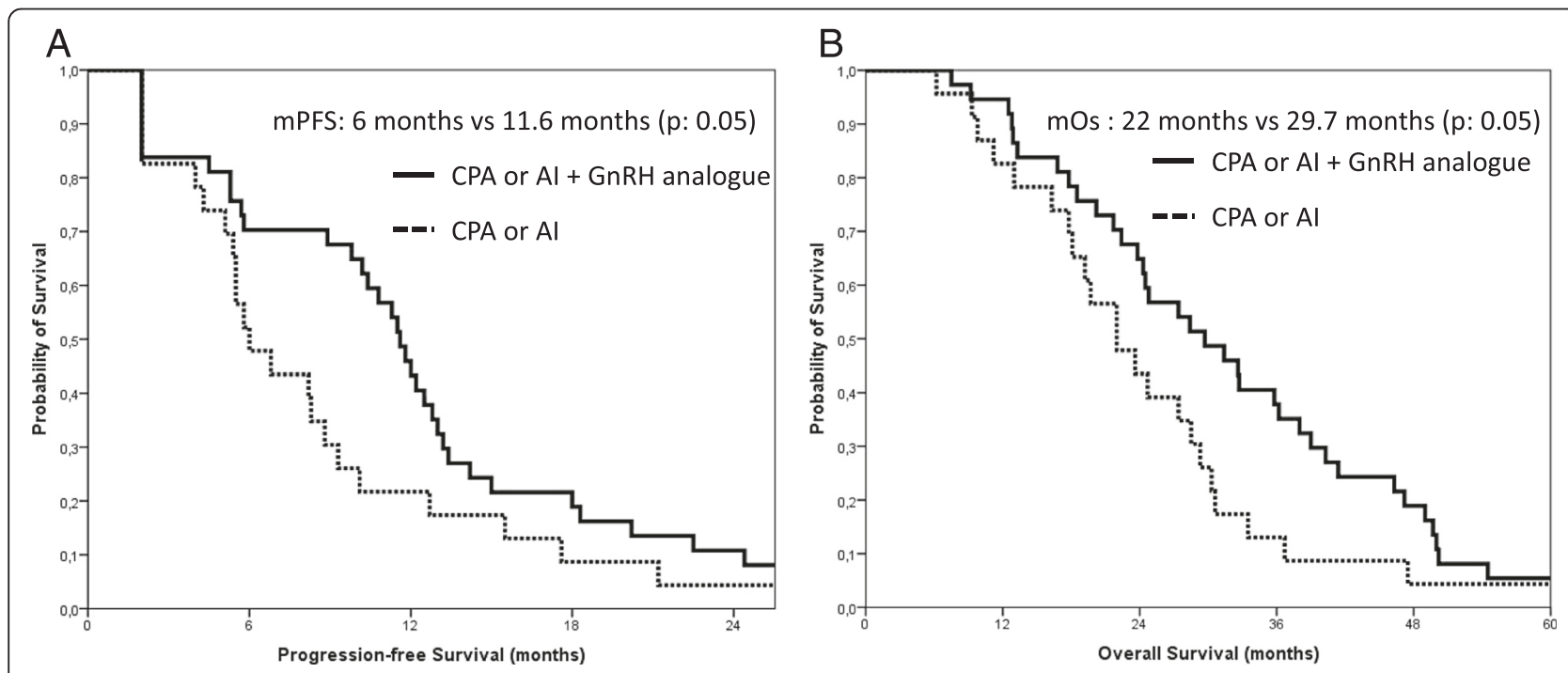

Fig. 1 Kaplan-Meier curves of a PFS and $\mathbf{b}$ OS comparing monotherapy (CPA or Al) versus combination therapy containing a GnRH analogue 
First and foremost, in interpreting our results and analyzing the therapeutic potential of $\mathrm{GnRH}$ analogues, we would like to draw the reader's attention to the line of reasoning that stimulated this study. We grouped patients treated with an AI or CPA as a monotherapy and compared them with patients that also received a $\mathrm{GnRH}$ analogue. As mentioned above, the logic behind this was the placement of $\mathrm{T}$ at the centerpiece of the endocrine network feeding MBC. Coherently, control of $\mathrm{T}$ levels is unsatisfactory in the case of exclusive use of CPA [23], or they even increase when AIs are administered in monotherapy [16-20]. Adding a GnRH analogue to peripherally acting antiestrogens and antiandrogens shares the same logic and produces the same output, that is, suppressing androgens [21, 23].

With the limitations of any retrospective and indirect comparison, we herein report a trend towards statistical significance favoring the use of $\mathrm{GnRH}$ analogue for all the survival endpoints considered. In order to put our results into context, it is worth considering that mPFS and mOS reported with combination therapy were fairly comparable with those previously observed with AIs, which were in the range of 4.4-13 and 33-39 months, respectively, independently on whether AIs were combined with a GnRH analogue or not [6-8]. These results are rooted, in our opinion, in the fact than more than half of the patients in this study received antiandrogen-based therapy mostly between the 1970s and 1980s [11-13]. With this therapeutic approach, mPFS was rather similar (8.9 months) to that observed with AIs, whereas mOS was shorter (24.3 months). Intuitively, this divergent pattern suggests that patients treated with antiandrogen-containing therapy were more likely to have received outdated postprogression treatments and possibly suboptimal supportive care, as already detailed [13]. In other words, the inclusion in the present analysis of patients treated at the dawning of antihormone therapy probably diluted the advantages potentially deriving from the use of $\mathrm{GnRH}$ analogues. Secondly and non-negligibly, five patients ( 20\%), of whom four were previously presented in [8], included in the monotherapy group who received an AI as a first-line therapy were rechallenged with an AI plus a GnRH analogue following disease progression. Notably, four out five of them confirmed or improved the best overall response observed in the previous therapeutic line with AI monotherapy. We cannot therefore exclude a role for such a sequential approach in diluting treatment efficacy and ultimately flattening survival curves.

\section{Conclusions}

We are aware that no firm conclusions can be drawn from this study, as the evidence provided does not meet criteria to settle the debate on the usefulness of $\mathrm{GnRH}$ analogues. On the other hand, however, clues emerging from this analysis encourage clinicians to consider GnRH analogues in the therapeutic continuum, irrespectively of the therapeutic "backbone" used. Finally, a provocative question arose that is whether, in pursuing the goal of sequential hormonal therapy for delaying chemotherapy, GnRH analogues shall deserve substantially increased consideration as singularly deliverable agents.

\section{Methods}

In the present study, we evaluated a population of 60 $\mathrm{mMBC}$ patients who had received an AI or CPA mostly in the first-line setting, administered as a monotherapy or combined with a $\mathrm{GnRH}$ analogue. The majority of patients were clinically managed at the "Regina Elena" National Cancer Institute, Rome. Individual patient data were reviewed in order to retrieve information on demographic factors, molecular pathology, therapies, and treatment outcomes. Patients received the following treatments: letrozole $2.5 \mathrm{mg}$ orally daily as a monotherapy or with leuprolide acetate or triptorelin acetate given intramuscularly at $3.75 \mathrm{mg}$ every 28 days, CPA $100 \mathrm{mg}$ twice a day as a monotherapy or combined with buserelin administered subcutaneously at $1500 \mu \mathrm{g}$ daily in three doses during the first week and then reduced to $600 \mu \mathrm{g}$ a day or Goserelin administered at $3.6 \mathrm{mg}$ subcutaneously every 28 days, exemestane $25 \mathrm{mg}$ once daily or anastrozole $1 \mathrm{mg}$ once a day. Tumor response was evaluated according to the criteria outlined by the International Union Against Cancer [24], the World Health Organization [25], or the Response Evaluation Criteria In Solid Tumors (RECIST 1.1) coherently to the period when patients were treated. Progression-free survival (PFS) and overall survival (OS) were calculated from the date of therapy initiation to the date of disease progression or death from any cause, respectively. PFS and OS were analyzed according to the Kaplan-Meier method. Comparisons between groups were carried out with the Tarone-Ware test. Statistical analyses were performed using SPSS statistical software version 20 (SPSS inc., Chicago IL, USA). This study was approved by the Ethics Committee of "Regina Elena" National Cancer Institute of Rome and was carried out according to the Helsinki Declaration.

\footnotetext{
Abbreviations

MBC: Male breast cancer; BC: Breast cancer; Als: Aromatase inhibitors; AR: Androgen receptor; CMF: Cyclophosphamide, methotrexate, and 5-fluorouracil; GnRH analogues: Gonadotropin-releasing hormone analogues; EC-D: Epirubicin, cyclophosphamide, docetaxel; FAC: 5-Fluorouracil, doxorubicin, and cyclophosphamide; FEC: 5-Fluorouracil, epirubicin, and cyclophosphamide: FSH: Follicle-stimulating hormone; LH: Luteinising hormone; T: Testosterone; mMBC: Metastatic male breast cancer; CPA: Cyproterone acetate; PFS: Progression-free survival; OS: Overall survival..
}

Competing interests

The authors declare that they have no competing interests. 


\section{Authors' contributions}

$L D L, R D M$, and MM-S conceived and designed the study. MM-S and LDL wrote the manuscript. LP, DS, MM, CAA, FB, VS, and PV collected and assembled the data. $L D L, L P, D S$, FB, and PV treated the patients. IS and MB performed the statistical analysis. VS and DS provided critical review of the manuscript. All authors read and approved the final manuscript.

\section{Acknowledgements}

We thank Tania Merlino and Ana Maria Edlisca for technical assistance. No funding was received for this research article.

\section{Author details}

"Division of Medical Oncology B, "Regina Elena" National Cancer Institute, Via Elio Chianesi 53, 00144 Rome, Italy. ${ }^{2}$ Scientific Direction, "Regina Elena" National Cancer Institute, Via Elio Chianesi 53, 00144 Rome, Italy. ${ }^{3}$ Biostatistics Unit, "Regina Elena" National Cancer Institute, Via Elio Chianesi 53, 00144 Rome, Italy. ${ }^{4}$ Department of Pathology, "Regina Elena" National Cancer Institute, Via Elio Chianesi 53, 00144 Rome, Italy. ${ }^{5}$ Division of Oncology, Spolverini Hospital, Ariccia, Italy. 'Leeds Institute of Cancer and Pathology, Wellcome Trust Brenner Building, University of Leeds, LS9 7TF Leeds, UK. ${ }^{7}$ Department of Medical Oncology, Campus Bio-Medico University of Rome, Rome, Italy.

Received: 19 March 2015 Accepted: 5 May 2015

Published online: 17 May 2015

\section{References}

1. Giordano SH, Cohen DS, Buzdar AU, Perkins G, Hortobagyi GN. Breast carcinoma in men: a population-based study. Cancer. 2004;101:51-7.

2. White J, Kearins O, Dodwell D, Horgan K, Hanby AM, Speirs V. Male breast carcinoma: increased awareness needed. Breast Cancer Res. 2011;13:219.

3. Shaaban AM, Ball GR, Brannan RA, Cserni G, Di Benedetto A, Dent J, et al. A comparative biomarker study of 514 matched cases of male and female breast cancer reveals gender-specific biological differences. Breast Cancer Res Treat. 2012;133:949-58.

4. Anderson WF, Jatoi I, Tse J, Rosenberg PS. Male breast cancer: a population-based comparison with female breast cancer. J Clin Oncol. 2010;28:232-9.

5. Eggemann $H$, Ignatov A, Smith BJ, Altmann U, von Minckwitz G, Röhl FW, et al. Adjuvant therapy with tamoxifen compared to aromatase inhibitors for 257 male breast cancer patients. Breast Cancer Res Treat. 2013;137:465-70.

6. Doyen J, Italiano A, Largillier R, Ferrero JM, Fontana X, Thyss A. Aromatase inhibition in male breast cancer patients: biological and clinical implications. Ann Oncol. 2010;21:1243-5.

7. Zagouri F, Sergentanis TN, Koutoulidis V, Sparber C, Steger GG, Dubsky P, et al. Aromatase inhibitors with or without gonadotropin-releasing hormone analogue in metastatic male breast cancer: a case series. Br J Cancer. 2013;108:2259-63.

8. Di Lauro L, Vici P, Del Medico P, Laudadio L, Tomao S, Giannarelli D, et al. Letrozole combined with gonadotropin-releasing hormone analog for metastatic male breast cancer. Breast Cancer Res Treat. 2013;141:119-23.

9. Zagouri F, Sergentanis TN, Chrysikos D, Zografos E, Rudas M, Steger G, et al. Fulvestrant and male breast cancer: a case series. Ann Oncol. 2013;24:265-6.

10. Zagouri F, Sergentanis TN, Chrysikos D, Dimopoulos MA, Psaltopoulou T. Fulvestrant and male breast cancer: a pooled analysis. Breast Cancer Res Treat. 2015;149:269-75

11. Lopez M. Cyproterone acetate in the treatment of metastatic cancer of the male breast. Cancer. 1985;55:2334-6.

12. Lopez M, Natali M, Di Lauro L, Vici P, Pignatti F, Carpano S. Combined treatment with buserelin and cyproterone acetate in metastatic male breast cancer. Cancer. 1993;72:502-5.

13. Di Lauro L, Vici P, Barba M, Pizzuti L, Sergi D, Rinaldi M, et al. Antiandrogen therapy in metastatic male breast cancer: results from an updated analysis in an expanded case series. Breast Cancer Res Treat. 2014;148:73-80.

14. Callari M, Cappelletti V, De Cecco L, Musella V, Miodini P, Veneroni S, et al. Gene expression analysis reveals a different transcriptomic landscape in female and male breast cancer. Breast Cancer Res Treat. 2011;127:601-10.

15. Giordano SH, Hortobagyi GN. Leuprolide acetate plus aromatase inhibition for male breast cancer. J Clin Oncol. 2006;24:e42-3.

16. Mauras N, O'Brien KO, Klein KO, Hayes V. Estrogen suppression in males: metabolic effects. J Clin Endocrinol Metab. 2000;85:2370-7.
17. T'Sjoen GG, Giagulli VA, Delva H, Crabbe P, De Bacquer D, Kaufman JM. Comparative assessment in young and elderly men of the gonadotropin response to aromatase inhibition. J Clin Endocrinol Metab. 2005;90:5717-22.

18. Bighin C, Lunardi G, Del Mastro L, Marroni P, Taveggia P, Levaggi A, et al Estrone sulphate, FSH, and testosterone levels in two male breast cancer patients treated with aromatase inhibitors. Oncologist. 2010;15:1270-2.

19. Leder BZ, Rohrer JL, Rubin SD, Gallo J, Longcope C. Effects of aromatase inhibition in elderly men with low or borderline-low serum testosterone levels. J Clin Endocrinol Metab. 2004;89:1174-80.

20. Burnett-Bowie SA, Roupenian KC, Dere ME, Lee H, Leder BZ. Effects of aromatase inhibition in hypogonadal older men: a randomized, double-blind, placebo-controlled trial. Clin Endocrinol (Oxf). 2009;70:116-23.

21. Maugeri-Saccà $M$, Barba M, Vici P, Pizzuti L, Sergi D, De Maria R, et al. Aromatase inhibitors for metastatic male breast cancer: molecular, endocrine, and clinical considerations. Breast Cancer Res Treat. 2014;147:227-35

22. Korde LA, Zujewski JA, Kamin L, Giordano S, Domchek S, Anderson WF, et al. Multidisciplinary meeting on male breast cancer: summary and research recommendations. J Clin Oncol. 2010;28:2114-22.

23. Labrie F, Bélanger A, Luu-The V, Labrie C, Simard J, Cusan L, et al. Gonadotropin-releasing hormone agonists in the treatment of prostate cancer. Endocr Rev. 2005:26:361-79.

24. Hayward JL, Carbone PP, Heuson JC, Kumaoka S, Segaloff A, Rubens RD. Assessment of response to therapy in advanced breast cancer. Cancer. 1977;39:1289-94.

25. Miller $A B$, Hoogstraten $B$, Staquet $M$, Winkler $A$. Reporting results of cancer treatment. Cancer. 1981;47:207-14.

\section{Submit your next manuscript to BioMed Central and take full advantage of:}

- Convenient online submission

- Thorough peer review

- No space constraints or color figure charges

- Immediate publication on acceptance

- Inclusion in PubMed, CAS, Scopus and Google Scholar

- Research which is freely available for redistribution 